\title{
Thermal Evaluation of a Parabolic Trough Solar Concentrator Using Three Different Receivers
}

\author{
Sangotayo, E. O. ${ }^{*} \quad$ Waheed, M. A. ${ }^{2} \quad$ Bolaji B.O. $^{3}$ \\ 1.Ladoke Akintola University of Technology, Ogbomoso, Department of Mechanical Engineering \\ 2.Federal University of Agriculture, Abeokuta, Department of Mechanical Engineering \\ 3.Federal University of Oye Ekiti, Department of Mechanical Engineering
}

\begin{abstract}
Energy demand, global warming from the fossil fuels and attempt to reduce greenhouse gas emission have placed the centre of attention on how to utilize an alternative sources of energy such as renewable energy technology This work presents the design, fabrication, and evaluation of the performance of Parabolic Trough Solar Concentrator (PTSC) as a source of heat energy. The PTSC is built, having the Supporting stand made of mild steel and reflector is made of the segmented mirror having a reflectivity of 0.85 , a rim angle of $90^{\circ}$ and aperture area of $2.5 \mathrm{~m}^{2}$ and with a concentration ratio of 11.7. The receiver pipes are made of three different materials; copper, aluminum, and stainless steel. The effects of shifts in focal lengths on the performance of the PTSC with three different receivers were investigated. The results reveal copper as a receiver tube conducts heat to the heat transfer fluid better than aluminum and stainless steel receivers. The focal length of $30 \mathrm{~cm}$ gave the best results compared to other values of 27 and $35 \mathrm{~cm}$ with a maximum temperature of $114.4{ }^{\circ} \mathrm{C}$. The experimental results revealed that useful heat gained, overall heat loss coefficient, collector efficiency factor, heat removal factor, collector and thermal efficiency were $147.8 \mathrm{~J}, 5.04 \mathrm{~W} / \mathrm{m}^{2} \mathrm{~K}, 0.05,15.05,0.032 \%$ and $15.5 \%$ respectively. The study shows that the Parabolic Trough Solar Concentrator as a source of heat energy gives a promising performance. This concentrator will reduce the dependence on the electric power supply, and it controls pollution emanating from fossil fuel, thereby reducing environmental problems.
\end{abstract}

Keywords: Parabolic Trough Solar Collector, Segmented Mirror, Efficiency, Receivers.

DOI: $10.7176 / \mathrm{JETP} / 9-5-03$

Publication date: June $30^{\text {th }} 2019$

\section{Introduction}

The solar thermal collector is an economical application of solar energy, a clean and environmentally friendly renewable resource. Instead of using electricity, oil, or gas as a source of heat, is an attractive alternative, mainly in places where electric power is not available. Parabolic cylindrical trough collector is one of the solar concentrator technologies for the transformation of solar energy into thermal drive. Blackened metal tube receiver is fitted on the focal plane of the cylinder, and the channel is rotated about its axis to monitor the motion of the sun. The metal tube transporting heat transfer fluid receives heat energy and gets heated. The hot heat transfer fluid is used for other applications. The performance of the trough collector is affected by different parameters such as aperture diameter, rim angle, the reflectivity of the reflector, absorber size, and shape. To enhance the performance of the cylindrical trough collector, researchers all over the world made sincere efforts to optimize the parameters affecting the performance of the system.

A tubular cavity receiver with air as heat transfer fluid in a parabolic trough solar concentrator system was analyzed (Bader et al., 2015) and found that the collector efficiency varies between 60 to $65 \%$. Kumaresan et al. (2012) investigated the performance of a solar parabolic trough collector with a thermal energy storage system. The instantaneous peak efficiency of $62.5 \%$ for the parabolic trough was obtained at 12.00 hours. Xiao et al. (2014) utilized a V-cavity absorber in linear parabolic trough solar collector and investigated heat transfer performance theoretically and experimentally. The results were in reasonable conformity with the experimental results. Sokhansefat et al., (2015) examined the impact of $\mathrm{Al}_{2} \mathrm{O}_{3}$ grain concentration in synthetic oil heat transfer working fluid and rate of heat transfer from the absorber tube to the working fluid in the concentrator. The study revealed the direct dependence of the volumetric concentration of nanoparticles in heat transfer working fluid on the convective heat transfer coefficient. Wu et al. (2014) proposed a coupled transient model for parabolic trough receiver. The results of the model reflected the average difference in the performance between indoor and outdoor experiments were within 6\%. Coccia et al., (2015) carried out the design, construction, and testing of a prototype of parabolic trough collector for industrial heat processes and the system is capable of working with de-mineralized water for temperature up to $85^{\circ} \mathrm{C}$.

Reddy and Satyanarayana (2008) developed a numerical model to examine the heat transfer characteristics of a solar parabolic trough receiver with porous inserts for different fluxes. Mokheimer et al., (2015) performed the optical and thermal analysis of parabolic trough collector under Dhahran's weather conditions. It was found that the system achieved the maximum and minimum optical efficiency of $73.5 \%$ and $61 \%$. Huang et al. (2012) did a performance simulation of a parabolic trough solar collector and built a new and quick investigative approach 
to determine the optical efficiency of the proposed system.

Ladgaonkar and Patil, (2014) performed a selective absorber coating of absorber tube for parabolic trough collector to investigate the performance of the system. The parabolic trough collector overall efficiency, without glass cover per period of two days and with glass cover per period of six days was $48.79 \%$ and $55.78 \%$. Wirz et al. (2014) built a detailed 3D heat transfer model of parabolic trough concentrators, and the properties of selective coatings and different designs of secondary concentrators were evaluated. Monte Carlo ray-tracing and computational fluid dynamics have been used to find the performance of parabolic trough receiver by Mwesigye et al., 2014) and revealed that the higher concentration ratio increases higher entropy generation. Exergy analysis was carried out to study the effects of operational and environmental parameters on the performance of Parabolic Trough Collectors (Padilla et al., 2015) and found that the highest exergy destruction is due to heat transfer between the sun and the absorber.

Energy demand, global warming from the fossil fuels and attempt to reduce greenhouse gas emission have placed the centre of attention on how to utilize alternative sources of energy such as renewable energy technology (Kotorkoshi et al.2015). It was observed that experimental analysis had not been carried out to assess the effect of the shift in the focal plane with different receiver's materials on the performance of Parabolic Trough Solar Concentrator in Ogbomoso climatic conditions. In this study, the design, construction, and evaluation of a parabolic trough solar collector are presented to examine the effect of the shift in the focal plane with different receiver materials in Ogbomoso environ.

\section{Design}

2.1 Design Parameters of Parabolic Trough Solar Concentrator, PTSC

The length of the parabolic trough, (standard length available in the market was selected) $\mathrm{L}=2.02 \mathrm{~m}$. The diameter of the adsorber pipe, $\mathrm{D}_{\mathrm{i}}=0.0325 \mathrm{~m}$, the geometric concentration level, $\mathrm{C}_{\mathrm{g}}=11.75$. This $\mathrm{C}_{\mathrm{g}}$ gives a high temperature at the efficiency of about $60 \%$ is as in equation (1), and the radius of the adsorber pipe is $0.0163 \mathrm{~m}$,

The radius of Adsorber, $\mathrm{r}_{\mathrm{a}}=\frac{D}{2}=\frac{0.0325}{2}=0.0163 \mathrm{~m}$

$\mathrm{C}_{\mathrm{g}}=\frac{A_{a}}{A_{r}}=\frac{\text { Aperturearea }}{\text { Adsorberarea }}=\frac{L \times w}{2 \pi r_{a} L}$

Where $r_{a}=0.0163 \mathrm{~m}, C_{g}=11.75, L=2.02 \mathrm{~m}$

$$
11.75=\frac{2.02 \times w}{2 \pi \times 0.0163 \times 2.02}
$$

Aperture width, $\mathrm{w}=11.75 \times 2 \pi \times 0.0163=1.204 \mathrm{~m} \simeq 1.20 \mathrm{~m}$

the adsorber pipe is placed at focal length (f) is as in equation (2) to minimize heat losses, then,

$$
f=h=\frac{d}{4} \text { or } \frac{w}{4}
$$

Using $\mathrm{d}=1.20 \mathrm{~m}, \mathrm{f}=\mathrm{h}=\frac{1.20}{4}=0.30 \mathrm{~m}$

Therefore $\mathrm{h}=0.30 \mathrm{~m}$, where $\mathrm{f}$ is the focal length and $\mathrm{h}$ is the collector depth, If the focal length is taken as $\mathrm{f}=30 \mathrm{~cm}$, the equation of the parabola is as in equation (3), $y^{2}=4 f x$.

The curve length s' of the parabola curve is obtained as in equation (4)

$$
s^{\prime}=\left[\frac{d}{2}\left\langle\sqrt{\left(\frac{4 h}{d}\right)^{2}}\right\rangle+1\right]+2 f \ln \left[\frac{4 h}{d}+\left\langle\sqrt{\left(\frac{4 h}{d}\right)^{2}}\right\rangle+1\right]
$$

(Fauziah et al, 2012) Using $\mathrm{f}=0.30 \mathrm{~m}, \mathrm{~d}=1.20 \mathrm{~m}, \mathrm{~h}=0.30 \mathrm{~m}$.

$$
S^{\prime}=2.260 \mathrm{~m}
$$

The rim angle can be calculated using equation (5),

$$
\cos \emptyset_{R}=\frac{2 f}{\sqrt{(0.5 w)^{2}+(d-f)^{2}}}-1
$$

where $\mathrm{w}=1.20 \mathrm{~m}, \mathrm{~d}=0.30 \mathrm{~m}, \mathrm{f}=0.30 \mathrm{~m}$

Therefore the rim angle $\emptyset_{R}=90^{\circ}$

The transmittance of the adsorber product for beam radiation is as given by equation (6). (Fauziah et al., 2012, Kumar, 2013)

$$
(\tau \alpha)_{b}=\frac{\tau \alpha}{1-(1-\alpha) \rho_{d}}
$$

Where $\tau$ is Transmittance of the receiver's absorber (copper) $=0.88, \propto$ is Absorbance of the receiver's absorber (copper) $=0.95, \rho_{d}$ is Reflectance of the cover for diffuse radiation (Glass mirror) $=0.94,(\tau \alpha)_{b}$ is Transmittance of adsorber product for the beam radiation, hence

$$
(\tau \alpha)_{b}=\frac{0.88 \times 0.95}{1-(1-0.95) \times 0.94} \quad=\frac{0.836}{0.953}=0.8772
$$




$\begin{array}{ll}\begin{array}{l}\text { 2.2 Specifications of Cylindrical Trough Collector } \\ \text { Descriptions }\end{array} & \text { Specifications } \\ \text { Rim Angle }(\phi \mathrm{r}) & 90^{\circ} \\ \text { Focal Length(f) } & 0.30 \mathrm{~m} \\ \text { Aperture width(Wa) } & 1.20 \mathrm{~m} \\ \text { The outer diameter of the copper tube (Do) } & 0.018 \mathrm{~m} \\ \text { The inner diameter of the copper tube (Di) } & 0.018 \mathrm{~m} \\ \text { Length of the cylindrical trough(L) } & 2.1 \mathrm{~meter} \\ \text { Effective Aperture Area(Aa) } & 2.42 \mathrm{~m}^{2} \\ \text { Concentration Ratio }(\mathrm{C}) & 11.7 \\ \text { Reflectivity of the collector }(\rho) & 0.9 \\ \text { Absorptivity of the copper tube }(\alpha) & 0.8 \\ \text { Transitivity of the copper tube }(\tau) & 0.8 \\ \text { Intercept factor }(\gamma) & 0.92\end{array}$

\subsection{Fabrication of Parabolic trough collector, PTC}

The PTC was constructed using a simple approach. The parabolic trough has components of a receiver and a support structure. The detailed description of each part is as described in this section:

1. Parabolic Trough: Plywood of dimensions $202 \mathrm{~cm} \times 135 \mathrm{~cm}$ was used to form the parabolic shape. The plywood was used to provide the mechanical strength to the parabolic trough. A maco was then gummed on the plywood over which segmented mirrors which are 27 in number with dimensions $(202 \mathrm{~cm} \mathrm{x} 5 \mathrm{~cm})$ were pasted over it. The segmented mirrors were gummed in such a way that it forms a curve of the parabola. The segmented mirrors were used because they have very high reflectivity of $96 \%$. The reflector made up of segmented mirrors gummed on plywood.

2. Adsorber tube: The adsorber tube is made of copper placed at the focal point of the parabolic trough. The copper tube has a length of $2.21 \mathrm{~m}$ with an internal and external diameter of $0.0325 \mathrm{~m}$ and $0.0343 \mathrm{~m}$, respectively. Copper, Aluminum, and Stainless steel absorber tube were used and painted black to absorb the solar radiation reflected by the reflector more efficiently.

3. Support Structure: The supporting frame was designed so that the majority of the weight was placed on the main support structure. The frame was made to be removed for disassembly and transportation purposes. The entire unit was mounted on a single frame for accessible transport site to site. Wheels were attached to the frame to allow easy short-range transportation such as in and out of the laboratory for testing. A jockey wheel was also mounted to assist with the short-range transport of the device and positioning for testing. A threaded strut was developed to hold the mirror at any desired angle. It was necessary for the correct alignment to the sun in any location.

\subsection{Experimental Method}

Experiments were conducted using the developed parabolic trough collector system as source heat to heat receivers. Copper, Aluminum and Stainless steel receivers were used with three different focal planes of 27, 30 and $35 \mathrm{~cm}$ of the collector. The system was mounted in North-South direction in the Department of Mechanical Engineering, LAUTECH, OGBOMOSO. (Lat. 8.1227 $\mathrm{N}$, Long. $4.2436^{\circ} \mathrm{E}$, Elevation of $347 \mathrm{~m}$ ). 12-channel temperature recorder with thermocouples was used to measure the ambient, reflector, adsorber outer and internal temperatures of the system. Solar radiation meter was used to record the intensity of radiation, and wind speed was measured using an environmental meter. Measurements were taken with an interval of 2 minutes between 9 am and 4 pm. The data for one of the typical days were taken for the evaluation of the performance of the PTSC system. Simultaneously, the variations of ambient, reflector, outer, and inner temperature were recorded using the temperature recorder placed at the different points of the trough. The data were recorded to evaluate the performance of the designed system. The photograph of the experimental set up of the system is shown in Figure 1.0 .

\section{Performance of Parabolic Trough Collector}

The performance analysis characterizes the solar field under different operating conditions for the system under study. The performance parameters used are the solar field efficiency and the useful heat output from the solar field.

\section{Optical Efficiency}

The optical efficiency, $\left(\eta_{o}\right)$ is the amount of radiation absorbed by the absorber tube divided by the amount of direct typical radiation incident on the aperture area. The optical efficiency is normal to the aperture $\left(\theta=0^{\circ}\right)$ is given in equation (7)

$$
\eta_{o}=\rho(\tau \alpha) \gamma
$$




\section{Thermal Efficiency}

The overall collector efficiency $\left(\eta_{c}\right)$ is the ratio of the useful output $Q_{u}[\mathrm{~W}]$ delivered by the collector to the global irradiance $I\left[\mathrm{~W} / \mathrm{m}^{2}\right]$ incident on the collector aperture area $A_{a}\left[\mathrm{~m}^{2}\right]$ is as given in equation (8)

$$
\eta_{c}=\frac{Q_{u}}{A_{a} * I_{b}}
$$

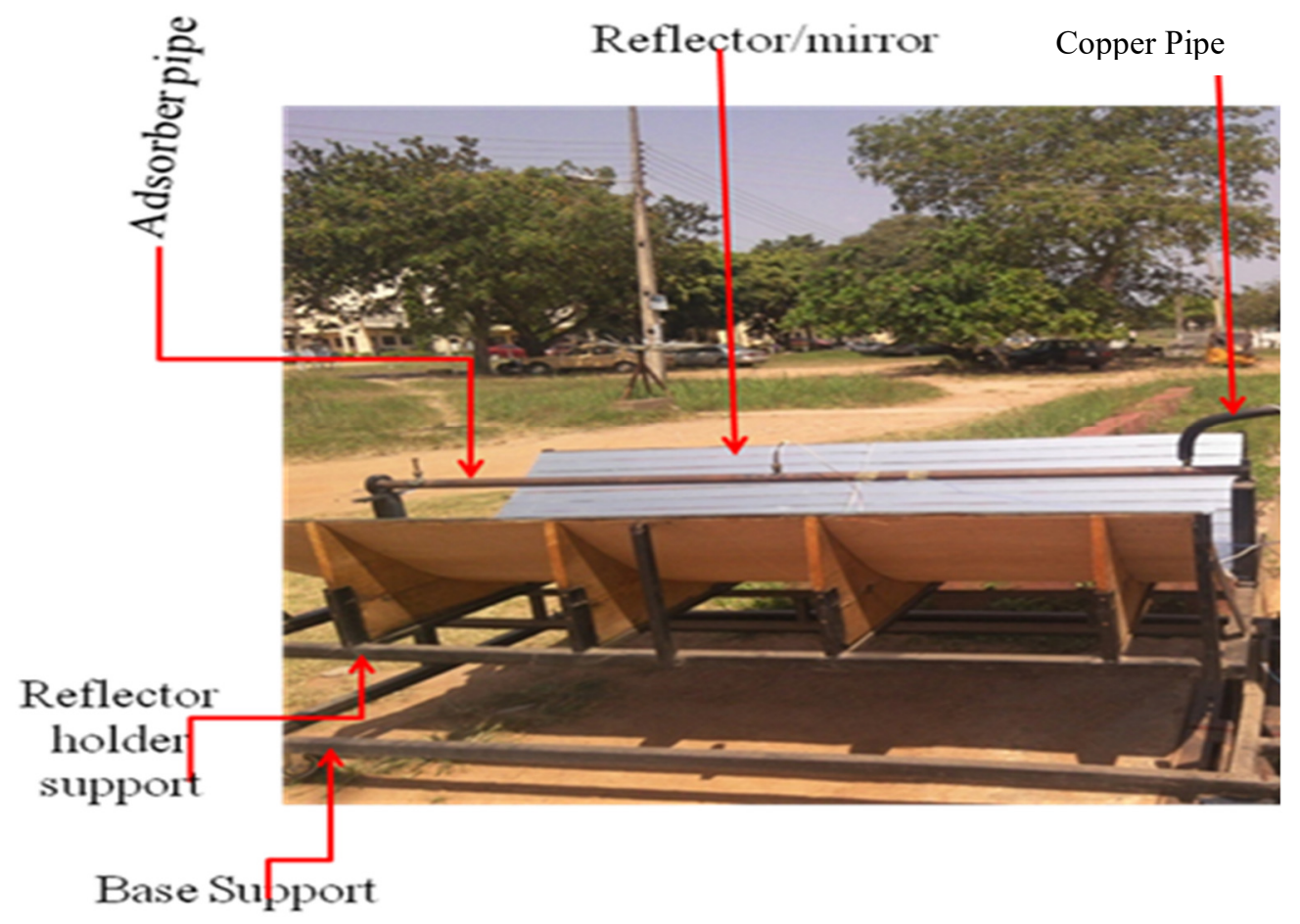

Figure 1.0: Photograph of the developed solar adsorption refrigeration system powered by parabolic trough solar concentrator

The useful output, $Q u$ of a concentrating collector, is expressed in equation (9)

$$
Q u=m \cdot C_{p} \cdot\left(T_{o}-T_{i}\right)=A_{a} \cdot I_{b} \cdot \eta_{o}-A_{a b s} \cdot U_{l} \cdot\left(T_{a b s}-T_{a}\right)
$$

\section{Results and Discussions}

Several observations were taken on the PTSC system in the Campus of Ladoke Akintola University of Technology, Ogbomoso. Data are plotted for different days as presented in Figures 2.0 to 15.0

The plot of ambient, reflector, adsorber outer and internal temperatures against the solar time using copper adsorber at a focal length of $30 \mathrm{~cm}$ is presented in Figure 2.0. The internal adsorber temperature increased from $31{ }^{\circ} \mathrm{C}$ at 9.00 hour to $114.1{ }^{\circ} \mathrm{C}$ around noon. It is evident that as the local time increases the internal temperature of the adsorber increases until the peak temperature of $114.1{ }^{\circ} \mathrm{C}$ is attained, after which it began to reduce. The temperatures of the reflector and outer surface of the adsorber kept the same sequence.

The graph of ambient, reflector, adsorber outer and internal temperatures against the solar time using aluminum adsorber at a focal length of $30 \mathrm{~cm}$ is presented in Figure 3. The internal adsorber temperature was increased from $27{ }^{\circ} \mathrm{C}$ at $9.00 \mathrm{~h}$ to $77^{\circ} \mathrm{C}$ around noon. It is shown that the internal temperature of the adsorber increases as the solar time increases from 9:00 am to 12:47 pm until when the peak internal adsorber temperature of $77^{\circ} \mathrm{C}$ is attained, after which it commenced decreasing. The temperatures of the reflector and the outer surface of the adsorber keep to the same pattern. 


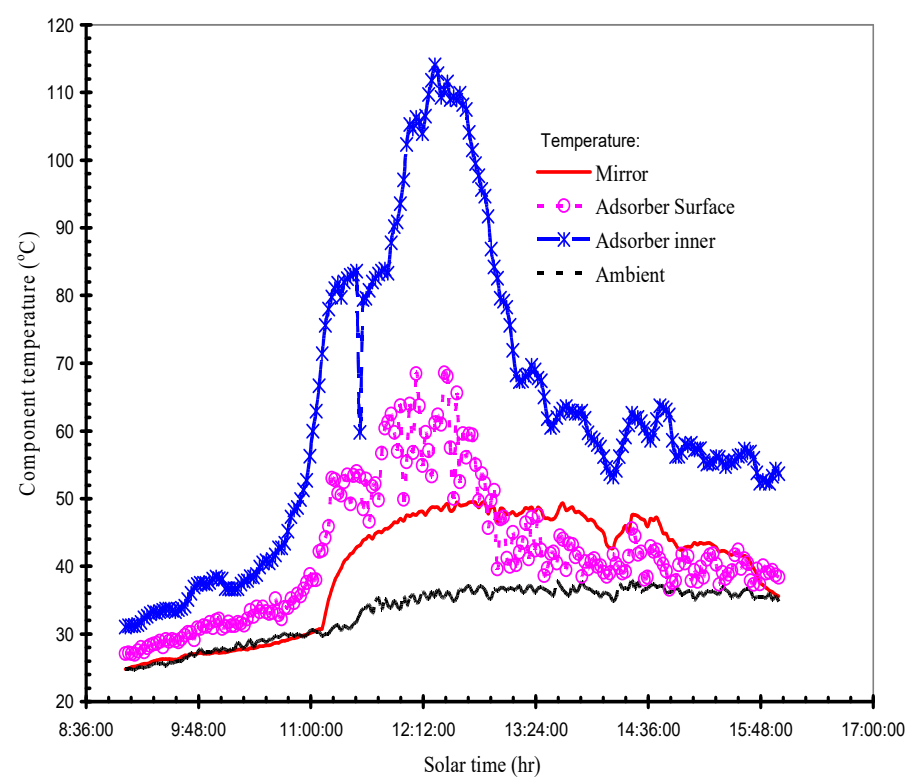

Figure 2: Graph of the ambient, adsorber outer and inner temperatures against the solar time, a copper receiver at a focal length of $30 \mathrm{~cm}$

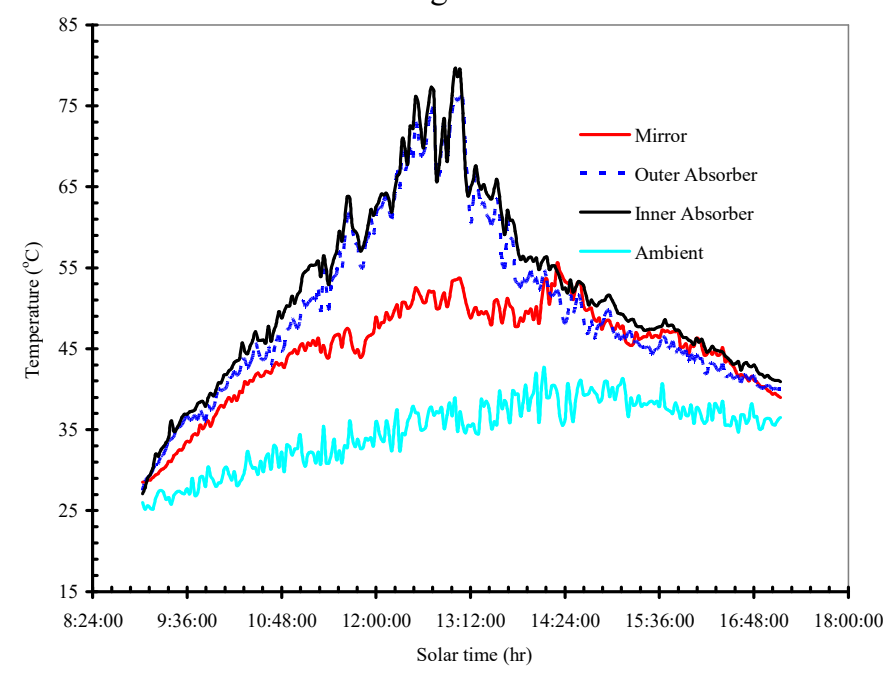

Figure 3: Graph of the ambient, adsorber outer and inner temperatures against the solar time, an Aluminum receiver at a focal length of $30 \mathrm{~cm}$

Variation of the ambient, reflector, adsorber outer and internal temperatures with the solar time using aluminum adsorber at a focal length of $30 \mathrm{~cm}$ is as presented in Figure 4. The adsorber outside temperature was increased from $28{ }^{\circ} \mathrm{C}$ at $8.24 \mathrm{~h}$ to $82{ }^{\circ} \mathrm{C}$ around $1 \mathrm{pm}$. It revealed that the outside temperature of the stainless adsorber increased with the solar time from 8:24 am to 1:10 pm when the peak outside adsorber temperature of 82 ${ }^{\circ} \mathrm{C}$ was reached, after which it began to decrease. The reflector and the inner surface temperature of the adsorber followed the same pattern. 


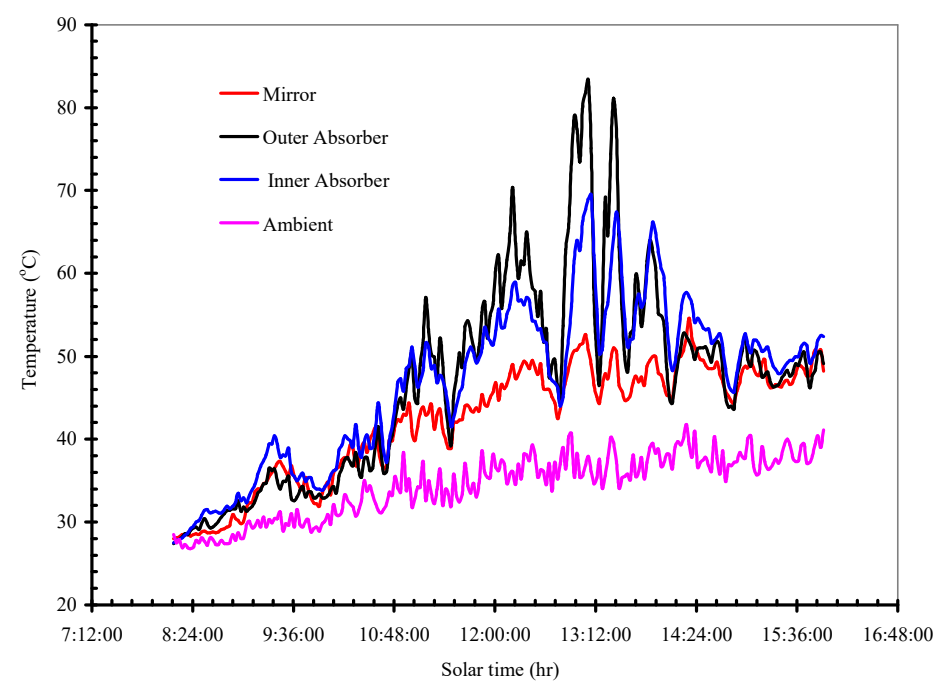

Figure 4: Graph of the ambient, adsorber outer and inner temperatures against the solar time, Stainless steel receiver, the focal length of $30 \mathrm{~cm}$

The graph of the inner absorber temperature versus the solar time with the different focal lengths of 27, 30, and $35 \mathrm{~cm}$ using stainless pipe is as presented in Figure 5. The Figures show that the internal temperature of the adsorber has a peak temperature of $77.8^{\circ} \mathrm{C}$ between 1:00 pm and 2:00 pm with the focal length of $30 \mathrm{~cm}$

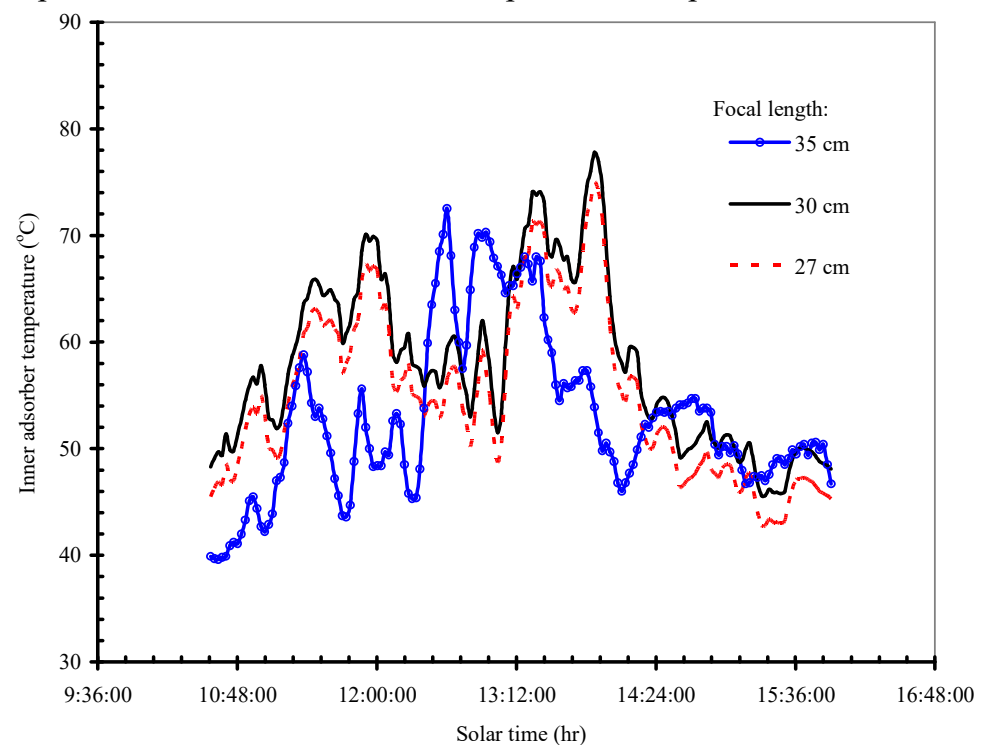

Figure 5: Variation of the inner adsorber temperature with the solar time for the stainless steel receiver at focal lengths of 27,30 and $35 \mathrm{~cm}$

The variation of the inner and outer adsorber temperature with the solar time at variable focal lengths of 27 , 30, and $35 \mathrm{~cm}$ for aluminum adsorber is presented in Figures 6 and 7. It compares the effect of the focal length on the aluminum adsorber temperature. As solar time increased, the temperature of the adsorber increased from 8:14 am to $1.00 \mathrm{pm}$ when the peak values of the temperature were obtained. The peak temperature of the inner adsorber was $87.7^{\circ} \mathrm{C}$ at $1: 00 \mathrm{pm}$ and outer adsorber of $78.7^{\circ} \mathrm{C}$ at the focal length of $30 \mathrm{~cm}$. The peak temperature of the inner was $79.5^{\circ} \mathrm{C}$, and the outer gave $76.3^{\circ} \mathrm{C}$ at the focal length of $35 \mathrm{~cm}$. The internal temperature of the absorber was $71.3^{\circ} \mathrm{C}$, and the outer was $68.1{ }^{\circ} \mathrm{C}$ at a focal length of $27 \mathrm{~cm}$. The temperatures of the adsorber and the solar intensity began to decrease after 1:00 pm with the increase in solar time. It is evident that for the three different focal lengths, $30 \mathrm{~cm}$ gives the highest value of the temperatures because it is one-fourth of the aperture width, 120 $\mathrm{cm}$ of the collector designed. The result supports the postulation of Balbir and Fauziah (2003) that the collector would be more efficient at a focal length of $1 / 4^{\text {th }}$ of the aperture width. 


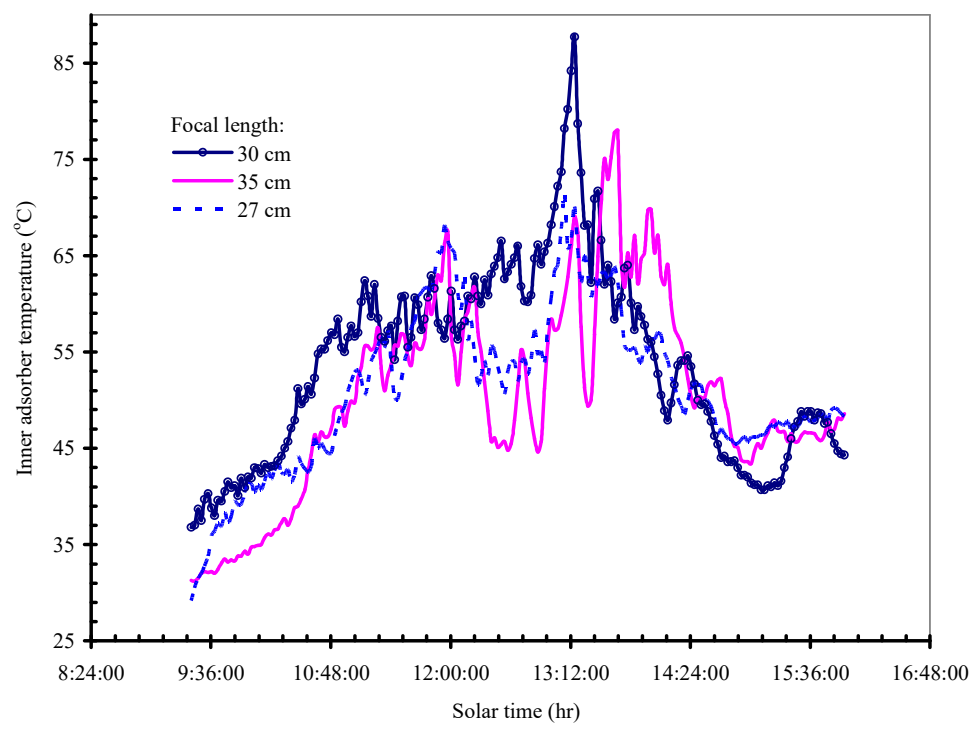

Figure 6: Variation of the inner adsorber temperature with the solar time at a different focal length of 27, 30 and $35 \mathrm{~cm}$ (aluminum receiver)

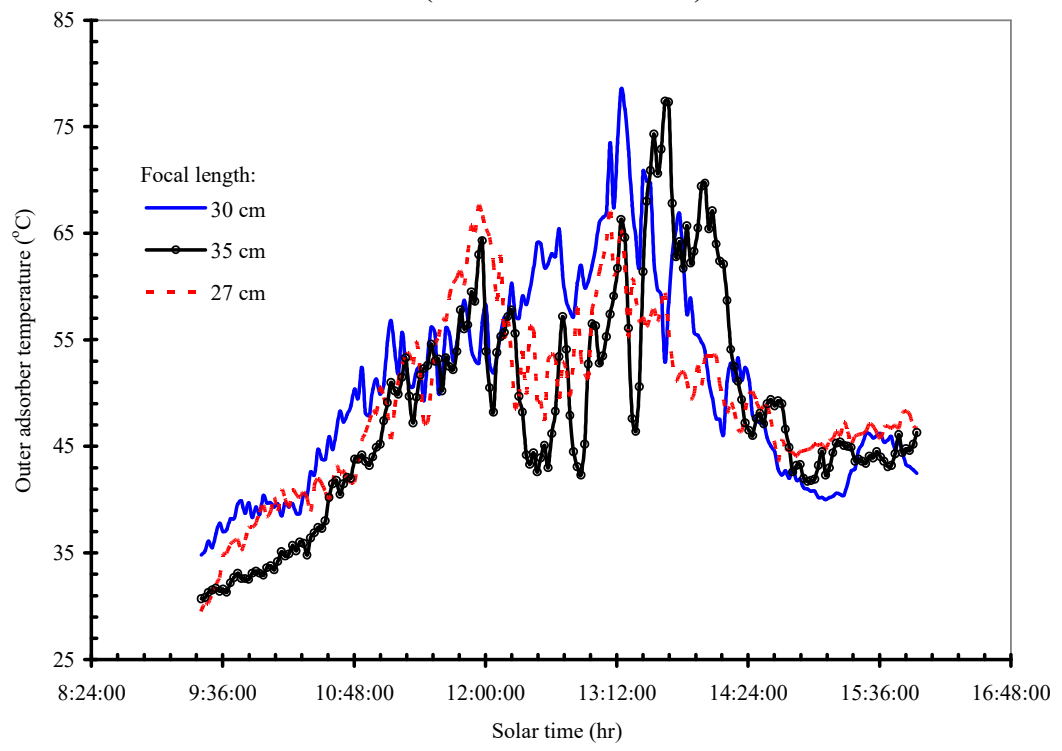

Figure 7: Variation of the outer adsorber temperature with the solar time at a different focal length of 27, 30 and $35 \mathrm{~cm}$ (aluminum receiver)

The plot of the instantaneous, thermal and collector efficiencies of the solar parabolic trough collector against local solar time at the focal lengths of $30 \mathrm{~cm}$ and $35 \mathrm{~cm}$ are presented in Figures 8, 9 and 10. It can be seen that as the local time increased, the efficiencies fluctuated with the solar intensity from 9:00 am to 4:00 pm. The focal length of $30 \mathrm{~cm}$, which is equal to $1 / 4^{\text {th }}$ of the aperture width of $120 \mathrm{~cm}$, gave higher values of efficiencies when compared with the focal length of $35 \mathrm{~cm}$. The fluctuation and dynamic nature of the efficiencies may be due to the dynamic nature of solar radiation, which is controlled by the weather conditions of different region and localities. 


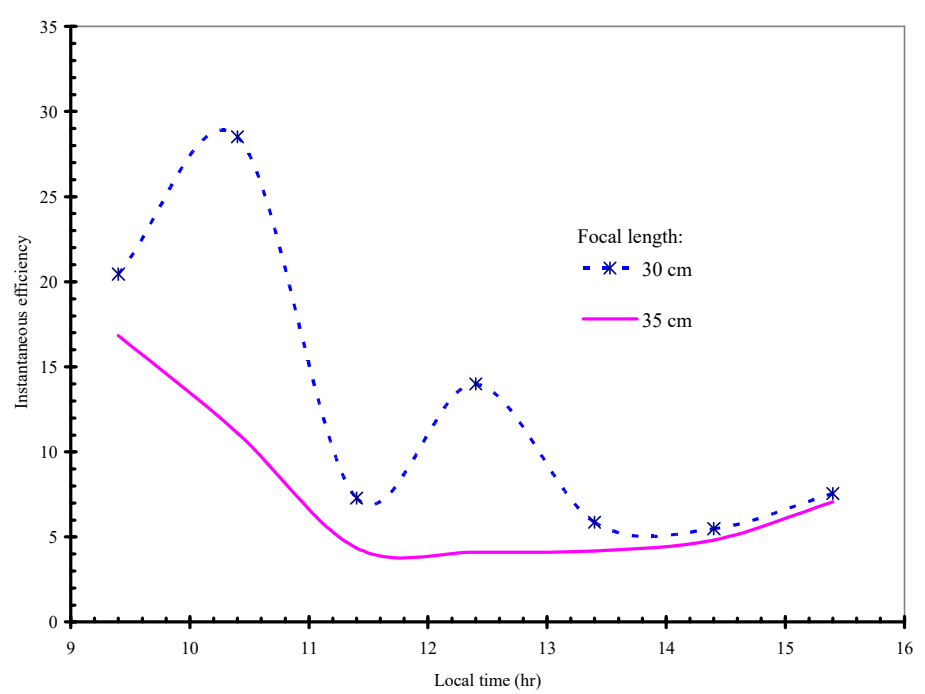

Figure 8: Plot of instantaneous efficiency against local time at a focal length of $30 \mathrm{~cm}$ and $35 \mathrm{~cm}$

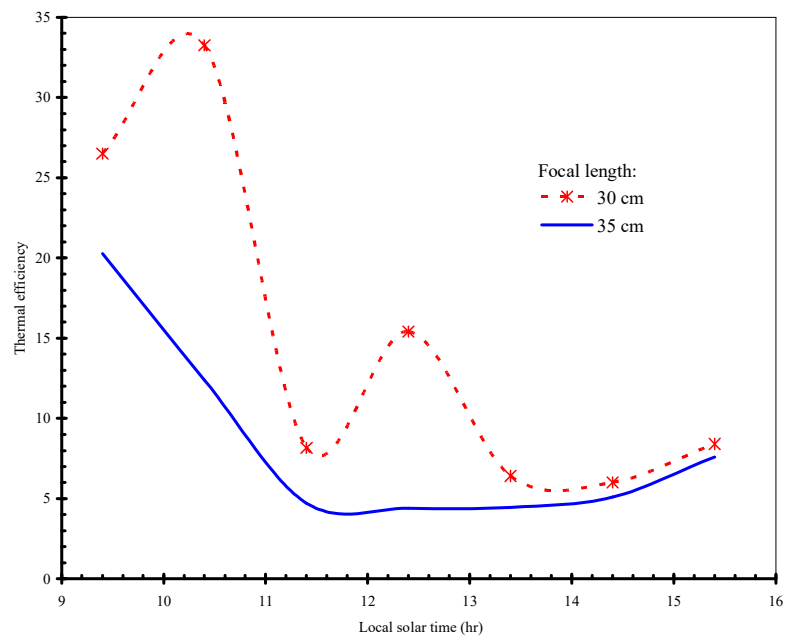

Figure 9: Plot of thermal efficiency against local time at a focal length of $30 \mathrm{~cm}$ and $35 \mathrm{~cm}$ :

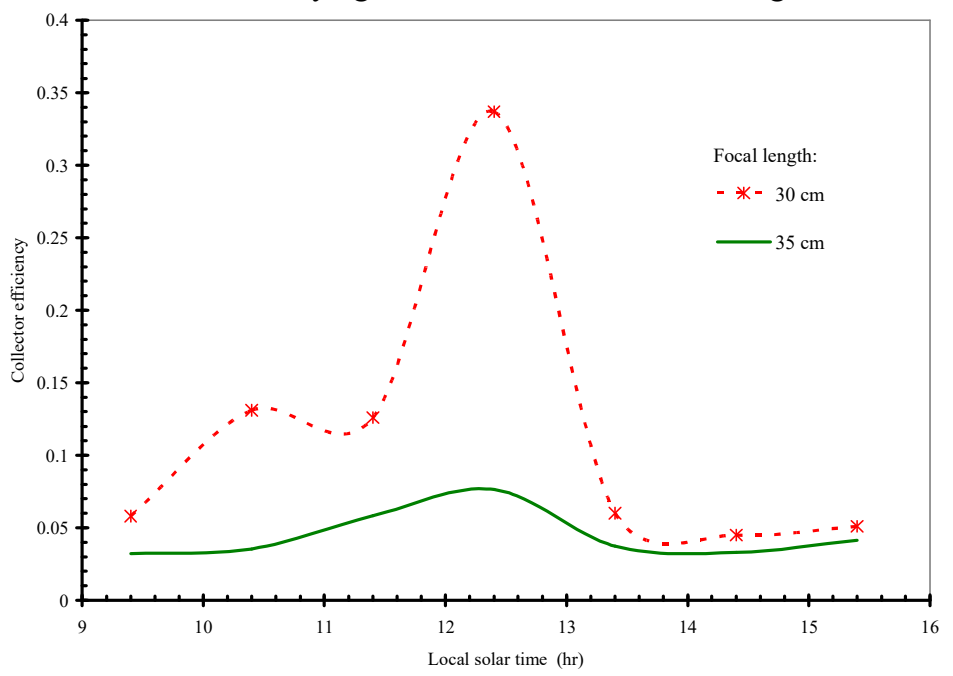

Figure 10: Plot of collector efficiency against local time at a focal length of $30 \mathrm{~cm}$ and $35 \mathrm{~cm}$

The comparison of the performance of PTSC with the three receivers' materials of copper, stainless and aluminum adsorber tubes at a focal length of $30 \mathrm{~cm}$. The relationships between the internal temperature of the copper, stainless, and aluminum adsorber tubes are shown in Figure 11. The result shows the relationship between the internal temperature of the copper, stainless, and aluminum adsorber tubes at a focal length of $30 \mathrm{~cm}$. Copper has a peak internal adsorber temperature of $114.4^{\circ} \mathrm{C}$ at $12: 30 \mathrm{pm}$ 


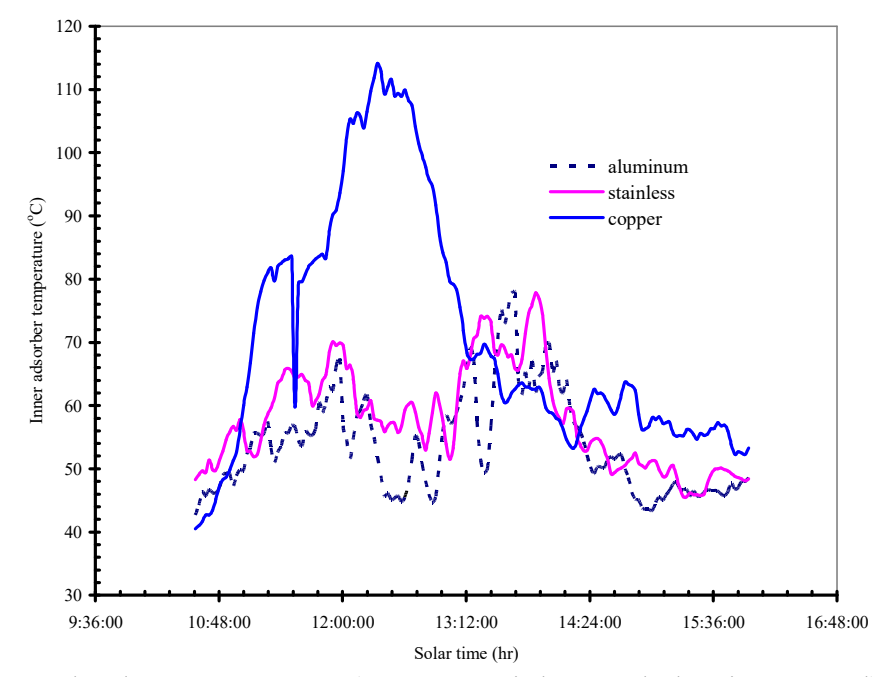

Figure 11: Plot of the inner adsorber temperature (copper, stainless and aluminum steel) against the solar time at the focal length of $30 \mathrm{~cm}$

The nature of solar radiation intensity and wind speed of the test rig climatic condition is presented in Figures 12 and 13. The solar radiation intensity improves with the local time, with a substantial change between 122.9 $\mathrm{W} / \mathrm{m}^{2}$ to $817.1 \mathrm{~W} / \mathrm{m}^{2}$ as presented in Figures 12. There is a sharp fluctuation between the time of 11:47 am to 3:59 $\mathrm{pm}$. The solar radiation intensity is attaining its maximum value of $836.8 \mathrm{~W} / \mathrm{m}^{2}$ at $1: 37 \mathrm{pm}$. The fluctuation of the intensity from 9:00 am to 4:00 pm, has substantial impacts on the temperatures achieved for the day. It determines the dynamic nature of the results obtained in this work. The effect of local time on wind speed is presented in Figure 13. The result shows that the wind speed fluctuates with the local time, and it reveals the dynamic nature of the weather conditions.

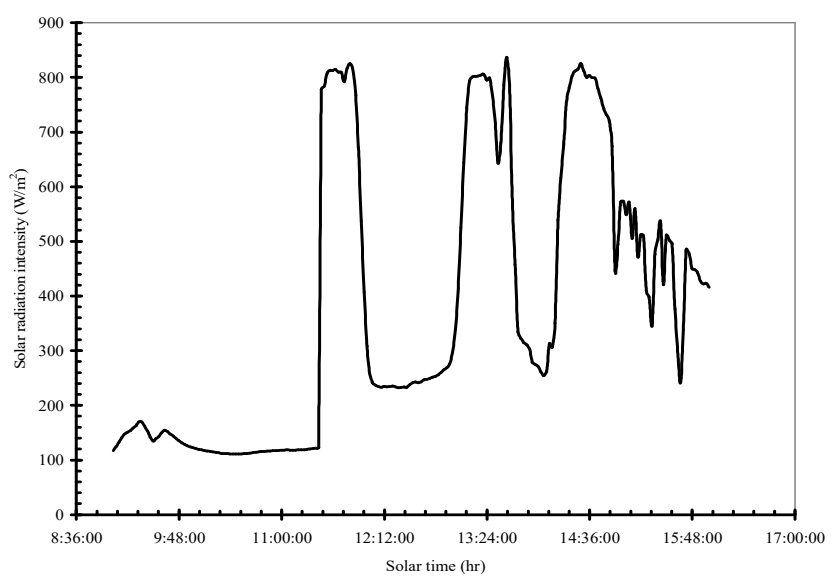

Figure 12: Plot of solar radiation intensity against solar time

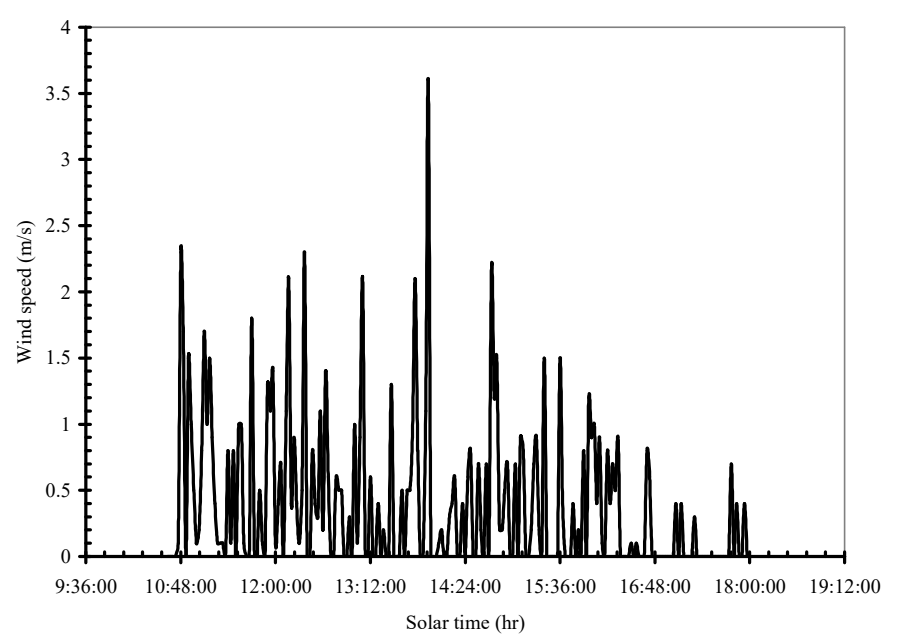

Figure 13: Plot of wind speed against solar time 


\section{Conclusions}

The following conclusions were drawn from the experiment carried out on the designed parabolic trough solar concentrator; A prototype of a Parabolic Trough Solar Concentrator was developed having an aperture width of $1.2 \mathrm{~m}$, collector length of $2.1 \mathrm{~m}$, rim angle of $90^{\circ}$ and focal length of $30 \mathrm{~cm}$.

The experimental results reveal that copper as a receiver tube conducts heat to the fluid better than aluminum, and stainless steel receiver, aluminum as an adsorber tube conducts heat to the fluid better than stainless steel adsorber. This work confirms that copper has highest ability to conduct the heat of $401 \mathrm{~W} / \mathrm{mK}$, aluminum has higher ability to conduct the heat of $205 \mathrm{~W} / \mathrm{mK}$, and stainless steel can conduct the heat of $16 \mathrm{~W} / \mathrm{mK}$, thermal conductivity. The focal length of $30 \mathrm{~cm}$, which is equal to $1 / 4^{\text {th }}$ of the aperture width of $120 \mathrm{~cm}$, gave the best results compared to other values of 27 and $35 \mathrm{~cm}$ with a maximum temperature of $114.4{ }^{\circ} \mathrm{C}$ around noon.

The performance of the system is found to be satisfactory in the local climatic conditions, and the useful heat gained, overall heat loss coefficient, collector efficiency factor, heat removal factor, collector and thermal efficiency were $147.8 \mathrm{~J}, 5.04 \mathrm{~W} / \mathrm{m}^{2} \mathrm{~K}, 0.05,15.05,0.032 \%$ and $15.5 \%$ respectively. The study has shown that the Parabolic Trough Solar Concentrator system will give a promising performance as a source of heat energy in southwestern climatic conditions of Nigeria. By manufacturing such type of solar concentrator adds a new dimension to the world of energy. This concentrator gives some amount of relief to the energy world by reducing the dependence on the electric power supply, and it controls pollution emanating from fossil fuel, thereby reducing environmental problems.

\section{Nomenclature}

PTSC - Parabolic trough solar concentrator

$\mathrm{Q}_{\mathrm{u}}$ - Useful heat output

$\mathrm{C}_{\mathrm{p}}$ - Specific heat capacity

$\mathrm{T}_{\mathrm{i}}$ - Inner Temperature

$\mathrm{I}_{\mathrm{b}}$ - Incident Solar Radiation

$\mathrm{T}_{\mathrm{a}}$ - Ambient temperature

$\eta$ - Thermal efficiency

$\mathrm{m}$ - Mass Flow Rate

$\mathrm{T}_{\mathrm{o}}$ - Outlet Temperature

$\mathrm{A}_{\mathrm{a}}$ - Aperture Area

$\tau$ - Transmittance of the receiver

$\propto$ - The absorbance of the receiver

$\rho_{d}$ - The reflectance of the cover for diffuse radiation

$(\tau \alpha)_{b}$ - The transmittance of adsorber product for the beam radiation

Acknowledgments: The financial assistance through Research Grant from the Institute of Food Security, Environmental Resources and Agricultural Research (IFSERAR), Federal University of Agriculture, Abeokuta (FUNAAB) is highly appreciated. The Research Grant number is UNAAB/IFSERAR/IRG 53.

\section{References}

Bader, R., Pedretti, A., Barbato, M., and Steinfeld, A. (2015) “An air-based corrugated cavity-receiver for solar parabolic trough concentrators”, Applied Energy, Vol-138, pp. 337-345.

Balbir, S. M. S., and Fauziah, S. (2003). Designing a Solar Thermal Cylindrical Parabolic Trough Concentrator by Simulation. International Rio3 Congress, World Climate and Energy Event. Rio de Janeiro, Brazil pp143149.

Coccia, G., Nicola, G. D. and Sotte, M. (2015) "Design, manufacture, and test of a prototype for a parabolic trough collector for industrial process heat," Renewable Energy, Vol. 74, pp.727-736.

Good, P., Ambrosetti, G., Pedretti, A. and Steinfeld, A. (2015), “An array of coiled absorber tubes for solar trough concentrators operating with air at $600^{\circ} \mathrm{C}$ and above", Solar Energy, Vol.111, pp. 378-395.

Gorantla, P., Janarthanan, B. and Chandrasekaran, J. (2016) Design, Fabrication, and Performance analysis of a low-cost cylindrical Trough collector with Aluminium Receiver. International Journal of Scientific \& Engineering Research, Volume 7, Issue 1, January-2016.

Huang, W., Hu, P. and Chen, Z. (2012) "Performance simulation of a parabolic trough solar collector," Solar Energy, Vol.86, pp.746- 755.

Kasaeian, A., Daviran, S., Azarian, R. D. and Rashidi, A. (2015) "Performance evaluation and nanofluid using capability study of a solar parabolic trough collector," Energy Conversion and Management, Vol.89, pp. 368-375.

Kotorkoshi I. M., Zulkifli Z. B. and Dasuki K. A. (2015) org Challenges and Prospect for the Development of Parabolic Trough Solar Collectors (PTC's) in Malaysian Environment, International Journal of Scientific and Research Publications, Volume 5, Issue 8, pp 1 - 7 
Kumaresan, G., Sridhar, R. and Velraj, R. (2012) "Performance studies of a solar parabolic trough collector with a thermal energy storage system," Energy, Vol. 47, pp. 395-402

Ladgaonkar, P.S. and Patil, A.M. (2014) "Development and Performance Evaluation of Selective Coating of Absorber Tube for Parabolic Trough Collector," International Journal of Application or Innovation in Engineering \& Management, Vol.3 (11), pp.169-174.

Mokheimer, E.M.A., Dabwan, Y.N., Habib, M.A., Said, S.A.M. and Al-Sulaiman, F.A. (2014) Techno-economic performance analysis of parabolic trough collector in Dhahran, Saudi Arabia, "Energy Conversion and Management," Vol.86, pp.622-633.

Mwesigye, A., Bello-Ochende, T. and Meyer, J.P. (, 2014) "Minimum entropy generation due to heat transfer and fluid friction in a parabolic trough receiver with non-uniform heat flux at different rim angles and concentration ratios", Energy, Vol. 73, pp.606-617.

Padilla, R. V., Fontalvo, A., Demirkaya, G., Martinez, A., and Quiroga, A. G. (2014) "Exergy analysis of parabolic trough solar receiver," Applied Thermal Engineering, Vol. 67(1-2), pp.579-586.

Reddy, K. S, and Satyanarayanaa, G. V. (2008) "Numerical Study of Porous Finned Receiver for Solar Parabolic Trough Concentrator," Engineering Applications of Computational Fluid Mechanics, Vol.2 (2), pp.172-184.

Sokhansefat, T., Kasaeian, A. B. and Kowsary, F. (2014) "Heat transfer enhancement in parabolic trough collector tube using $\mathrm{Al}_{2} \mathrm{O}_{3}$ /synthetic oil nanofluid", Renewable and Sustainable Energy Reviews, Vol.33, pp.636-644,

Wirz, M., Petit, J., Haselbacher, A. and Steinfeld, A. (2014) "Potential improvements in the optical and thermal efficiencies of parabolic trough concentrators" Solar Energy, Vol.107, pp.398-414.

Wu, Z., Li, S. Yuan, G. Lei, D. and Wang, Z. (2014) “Three- dimensional numerical study of heat transfer characteristics of parabolic trough receiver," Applied Energy, Vol.113, pp.902-911.

Xiao, X., Zhang, P., Shao, D.D. and Li, M. (2014) "Experimental and numerical heat transfer analysis of a Vcavity absorber for linear parabolic trough solar collector.” Energy Conversion and Management, Vol. 86, pp. 49- 59 .

\begin{abstract}
About the Authors
E.O. Sangotayo is a Lecturer at the Department of Mechanical Engineering, Faculty of Engineering and Technology, Ladoke Akintola University of Technology, Ogbomoso-Nigeria and his area of specialization is thermo-fluid, heat transfer and energy studies. He received his academic training at the Ladoke Akintola University of Technology (for his B.Tech. and M.Tech) and his Ph.D. at the Federal University of Agriculture, AbeokutaNigeria. He is a member of the Nigeria Society of Engineers; a COREN registered engineer and member of America Society of Mechanical Engineers
\end{abstract}

M.A. Waheed is a Professor of thermo-fluid at the Department of Mechanical Engineering, College of Engineering, University of Agriculture, Abeokuta-Nigeria and his area of specialization is thermo-fluid, heat and mass transfer, computational fluid mechanics, and energy studies. He undertook his academic training at the University of Ilorin (for his B.Eng. and M.Eng.), Achem; and Germany University (for his Ph.D.). He is a member of many professional bodies and a COREN registered engineer. He has served as the Director of Academic Planning and Deputy Vice-Chancellor Academic, Federal University of Agriculture, Abeokuta-Nigeria, FUNAAB.

B. O. Bolaji is a Professor at the Department of Mechanical Engineering, Federal University Oye-Ekiti. He researches Environment-Friendly Refrigeration Systems, Renewable Energy Systems, Solar Thermal, and Solar Power Systems. His current project is 'Studies of Thermodynamic Properties and Energy Performance of RE170 and R510A Refrigerants in Vapour Compression Refrigeration System.' He undertook his academic training at the Federal University of Technology, Akure (for his B.Sc. M.Sc. and Ph.D.). He is a member of many professional bodies and a COREN registered engineer. 